\title{
Çeşitli klinik örneklerden izole edilen gram negatif gsbl pozitif bakterilerin antibiyotiklere direnç oranları
}

\section{Antibiotics resistance rates of gram negative esbl positive bacteria isolated from various clinical specimens}

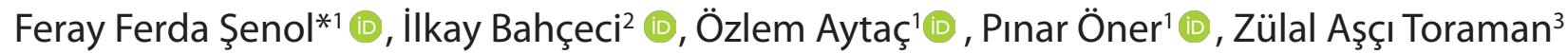

'Elazığ Fethi Sekin Şehir Hastanesi, Mikrobiyoloji Laboratuvarı, Elazığ/ TÜRKIYE ${ }^{2}$ Recep Tayyip Erdoğan Üniversitesi, Tıp Fakültesi, Tıbbi Mikrobiyoloji Anabilim Dalı, Rize/TÜRKiYE ${ }^{3}$ Fırat Üniversitesi, Tıp Fakültesi, Tıbbi Mikrobiyoloji Anabilim Dalı, Elazığ/TÜRKiYE

\section{öz}

Amaç: Genişlemiş Spektrumlu Beta Laktamaz (GSBL) pozitif mikroorganizmaların neden olduğu enfeksiyonların tedavisindeki zorluklar günümüzde en önemli sağlık sorunlarından biridir. çeşitli bakteriyolojik kültürlerinden izole edilen Gram negatif GSBL pozitif bakterilerin örnek türüne göre ampirik ve semptomatik tedaviye etkili antibiyotiklerin belirlenmesi amaçlanmıştır.

Gereç ve Yöntem: Bu çalışma 1 Ağustos 2019-1 Şubat 2020 tarihleri arasında çeşitli servis ve polikliniklerden rutin mikrobiyoloji laboratuvarına yollanan idrar, kan, yara, balgam, eklem sıvısı, plevral sıvı örneklerinden izole edilen bakteriyel etkenler ve antimikrobiyal duyarlılıkların retrospektif araştıııması ile yapılmıştır. Gram negatif GSBL pozitif bakterilerin tanımlanmaları ve antibiyotik duyarlıık testleri konvansiyonel yöntem ve MicroScan (Beckman Coultre, USA ) otomatize sistem ile yapılmıştır.

Bulgular: Laboratuvara gönderilen 13,968 klinik örnekten izole edilen 1735 Gram negatif bakterinin 1041 (\%60)'i GSBL pozitif idi. 1041 örneğin; 901 (\%86,55)'i idrar, 47 (\%4,51)'si Trakeal aspirat, 35 (\%3,36)'i yara idi. GSBL pozitif bakterilerin en sık izole edilenleri 732(\%70,3) ile Escherichia coli, 249(\%23,9)'u Klebsiella pneumonia, 22(\%2,11)'si Proteus mirabilis oluşturmaktaydı. Bu bakterilerin tamamı ampisilin, ampisilin-sulbaktam ve sefalosporin grubu antibiyotiklere dirençli iken bakterilerin en duyarlı olduğu grup ise karbapenem grubu antibiyotikler idi.

Sonuç: Gram negatif bakterilerde, antibiyotiklere dirençli izole edilen suşların oranlarındaki artış, kullanılabilecek tedavi seçeneklerini oldukça kısıtlamaktadır. Özellikle çoklu antibiyotik dirençli, sıkıkla toplum ve hastane kökenli enfeksiyonlara neden olan Gram negatif GSBL pozitif bakterilerin antibiyotik direnç durumlarının belirlenmesi güncel direnç oranını ortaya çıkaracağı gibi tedavi başarısının artııımasında yardımcı olacaktır. Her kurum kendi antibiyotik direncini saptayarak ülke verilerine katkı sunmalıdır.

Anahtar Kelimeler: Gram negatif bakteri; GSBL pozitif; antibakteriyel direnç.

Sorumlu Yazar*: İlkay Bahçeci, Recep Tayyip Erdoğan Üniversitesi, Tıp Fakültesi, Tıbbi Mikrobiyoloji Anabilim Dalı, Rize/ TÜRKiYE

E-mail: bahceciie@hotmail.com

ORCID: 0000000336621629

Gönderim: 22.06.2021 kabul: 22.11.2021

Doi: $10.18663 /$ tjcl.956156 


\begin{abstract}
ABSRACT
Aim: The difficulties in the treatment of infections caused by Extended Spectrum Beta-Lactamase (ESBL) positive microorganisms are one of the most important health problems today. In this study, it was aimed to determine the antibiotics effective in empirical and symptomatic treatment according to the sample type of Gram negative ESBL positive bacteria isolated from various bacteriological cultures.
\end{abstract}

Materials and Methods: This study was carried out by retrospective investigation of bacterial agents and antimicrobial susceptibility various samples sent to routine microbiology laboratory from various services and outpatient clinics between 1 August 2019 and 1 February 2020. Identification of Gram-negative ESBL-positive bacteria and antibiotic susceptibility tests were performed using the conventional method and MicroScan (Beckman Coultre, USA) automated system.

Results: Of the 1735 Gram-negative bacteria isolated from 13,968 clinical samples sent to the laboratory, 1041 (60\%) were ESBL positive. 1041 for example; 901 (86.55\%) were urine, 47 (4.51\%) were aspirate, 35 (3.36\%) were wounds. Escherichia coli with 732 (70.3\%) of ESBL positive bacteria, Klebsiella pneumonia with 249 (23.9\%) and Proteus mirabilis with 22 (2.11\%) were the most frequently isolated bacteria. While all of these bacteria were resistant to ampicillin-sulbactam, cephalosporin group antibiotics, the group to which the bacteria were most susceptible was carbapenem group antibiotics.

Conclusion: Determining the antibiotic resistance status of Gram-negative ESBL-positive bacteria, which are resistant to multiple antibiotics and frequently cause infections, will reveal the current resistance rate and will help increase the success of treatment. Each institution should contribute to country data by detecting its own antibiotic resistance.

Keywords: Gram negative bacteria; ESBL positive; antibacterial resistance.

\section{Giriş}

Antibiyotikler, mikroorganizmalara bağlı olarak gelişen enfeksiyon hastalıklarının tedavisinde kullanılan ilaçlardır. Son yıllarda yapılan birçok çalışmada bu grup ilaçların tüketimindeki artışın bir sonucu olarak toplum kaynaklı enfeksiyon etkenlerinde antibiyotiklere karşı direncin giderek arttığı görülmektedir [1]. Gram negatif bakterilerde özellikle de Escherichia coli (E. Coli) ve Klebsiella spp. de antibiyotiklere karşı gelişen direnç oluşum mekanizmalarının başında Genişlemiş Spektrumlu Beta Laktamaz (GSBL) enzim üretimi gelmektedir [1].

Genişlemiş Spektrumlu Beta Laktamaz enzimleri; sefotaksim, seftriakson, seftazidim, aztreonam ve oksiimino- $\beta$-laktamlara direnç kazandıran plazmid üzerinden taşınan enzimlerdir [2]. GSBL enzimi ilk kez 1983 yılında Klebsiella pneumonia (K. pneumoniae) suşunda Almanya'da tanımlanmış ve ilk dönemlerde beta-laktamaz enzimlerinden en fazla saptanan GSBL tipleri; TEM ve SHV grubu enzimlerdir iken son yıllarda CTX-M tipi ciddi artış göstermiştir. [2]

Genişlemiş Spektrumlu Beta Laktamaz üreten bakteriler; sepsis, üriner sistem enfeksiyonları, solunum yolu enfeksiyonları başta olmak üzere, intraabdominal enfeksiyonlar, yara yeri enfeksiyonları ve menenjite neden olabilmektedir. GSBL üreten bakteriler sefalosporin gruplarından üçüncü ve dördüncü kuşaklara in vitro duyarlı olsalar bile tedavide kullanımlarında başarısızlık görülebilir [3]. GSBL pozitif bakterilerle oluşan enfeksiyonların tedavisinde beta-laktam/beta-laktamaz inhibitör kombinasyonları, florokinolonlar, aminoglikozidler, sefamisinler ve karbapenemler etkili olabilir [3].

Bu çalışmada, XXX Hastanesi, Klinik Mikrobiyoloji Laboratuvarı́na 1 Ağustos 2019-1 Şubat 2020 tarihleri arasında gönderilen çeşitli klinik örneklerinden izole edilen Gram negatif GSBL pozitif bakterilerin örnek çeşitliliğine göre antibiyotiklere karşı direnç durumlarının belirlenmesi amaçlanmıştır.

\section{Gereç ve Yöntem}

1 Ağustos 2019-1 Şubat 2020 tarihleri arasındalaboratuvarımıza gönderilen servis ve poliklinik hastalarına ait klinik örneklerden (idrar, balgam, kan, yara, aspirat, eklem sıvısı) izole edilen 1041 Gram negatif GSBL pozitif bakterinin antibiyotik duyarlılık sonuçları geriye dönük retrospektif olarak değerlendirilmiştir. Bakterilerin tanımlanması, antibiyotik duyarlılık testleri ve GSBL nin tespiti konvansiyonel yöntemler ve MicroScan otomatize sistem (Becman Coulter, USA) ile yapılmış ve sonuçlar European Committee on Antimicrobial Susceptibility Testing (EUCAST) Version 9.0, 2019 kriterleri doğrultusunda değerlendirilmiştir [4]. Ayrıca GSBL pozitifliğinin tanımlanmasında çift disk sinerji ve kombine disk testleri de kullanılmıştır. Çift disk sinerji testi, amoksisilin-klavulanat ile seftazidim, sefotaksim ve aztreonam 
diskleri arasındaki uzaklık $20 \mathrm{~mm}$ ve $30 \mathrm{~mm}$ olmak üzere iki şekilde yapılmıştır. Klavunata doğru bozulmuş üreme GSBL pozitif olarak kabul edilir. Kombine disk yönteminde seftazidim/klavulanik asit $(30 / 10 \mu l) v e$ seftazidim $(30 \mu)$ yerleştirilir. $36^{\circ} \mathrm{C}$ 'de 24 saat inkübasyondan sonra, seftazidim ve seftazidim/klavulanik asit diskinin inhibisyon zon çapının, $5 \mathrm{~mm}$ artması GSBL pozitif kabul edilir.

Verilerde örnek sayısı n olarak gösterilmiş ve yüzde olarak hesaplanmıştır. Verilerin istatiksel analizinde SPSS (Statistical Packages of Social Sciences, SPSS for Windows, Version 21.0, Chicago, IC, USA) paket programı kullanılmıştır.

Bu çalışma için Fırat Üniversitesi Tıp Fakültesi Grişimsel Olmayan Klinik Etik Kurulu'ndan onay (Karar No: 07-20 Tarih: 29.04.2019) alındı. Çalışma Helsinki Deklerasyonu Prensipleri'ne uygun olarak yapıldı.

\section{Bulgular}

Laboratuvara gönderilen 13,968 klinik örneğin 1735'inde Gram negatif bakteri üremiştir. Bu örneklerden 1041'i GSBL pozitif olarak saptanmıştır. 1041 örneğin 732'si (\%70,31) E.coli, 249'u $(\% 23,91)$ K.pneumoniae, 22'si $(\% 2,11)$ P.mirabilis, 9'u $(\% 0,86)$ E.cloaca, 9'u (\%0,86 ) Serratia spp., 14'ü $(\% 1,34)$ C.freundi, 5'i $(\% 0,48)$ K.oxytoca, 1'i $(\% 0,096)$ Pantobacter spp. olarak izole edilmiştir. Klinik örneklerden en fazla E. coli izole edilmiştir. Suşların klinik örneklere göre dağı̆ımı Tablo 1'de gösterilmiştir. Karbapenem grubu antibiyotikler tüm bakteri türlerine en etkili antibiyotikler olarak saptanırken; izole edilen suşların tamamı ampisiline, ampisilin-sulbaktam ve sefalosporinlere dirençli olarak bulunmuştur. Çalışma grubunda yer alan diğer antibiyotiklerin direnç/duyarlılıkları örneğin türü ve izole edilen bakteriye göre farklılıklar göstermiştir. Çalışmamızda yer alan plevral sıvı örneğinin iki adet, eklem sıvısı örneğinin bir adet olasından dolayı değerlendirmeye alınmamıştır. Gram negatif GSBL pozitif bakterilerin örnek türü, poliklinik ve servis hastası olmalarına göre antibiyotik direnç oranları Tablo 2, Tablo 3, Tablo 4, Tablo 5 de verilmiştir.

\begin{tabular}{|c|c|c|c|c|c|c|c|c|}
\hline ÖRNEKTÜRÜ & E.coli & K. pneumonia & K. oxytoca & S. marcescens & E. cloaca & P. mirabilis & C. freundi & Pantobacter spp. \\
\hline İdrar & 667 & 188 & 3 & - & 8 & 21 & 14 & - \\
\hline Balgam & 8 & 6 & 1 & - & - & - & - & - \\
\hline Kan & 23 & 17 & - & - & - & - & - & - \\
\hline Yara & 22 & 8 & 1 & 3 & - & - & - & 1 \\
\hline Aspirat & 10 & 29 & - & 6 & 1 & 1 & - & - \\
\hline Plevral sıVı & 2 & - & - & - & - & - & - & - \\
\hline Eklem sIVISI & - & 1 & - & - & - & - & - & - \\
\hline TOPLAM & 732 & 249 & 5 & 9 & 9 & 22 & 14 & 1 \\
\hline
\end{tabular}

\begin{tabular}{|c|c|c|c|c|c|c|c|c|c|c|c|c|c|}
\hline Üreyen bakteri & $P / S(n)$ & AMC\% & GN \% & AK \% & LEV \% & CiP \% & FOS $\%$ & NITRO \% & SXT \% & E\% & iMP \% & MEM \% & COL \% \\
\hline \multirow[t]{2}{*}{ E. coli } & $\mathrm{P}(359)$ & 61,0 & 36,4 & 5,5 & 55,9 & 62,9 & 4,1 & 9,1 & 59,0 & 8,35 & 2,2 & 2,7 & 8,6 \\
\hline & S (308) & 61,3 & 47,7 & 9,4 & 78,2 & 92,2 & $\% 12,6$ & 19,1 & 64,2 & 11,3 & 1,6 & 2,9 & 8,4 \\
\hline \multirow[t]{2}{*}{ K pneumonia } & $P(76)$ & 65,7 & 35,5 & 14,4 & 27,6 & 43,4 & 14,4 & 34,2 & 51,3 & 6,5 & 3,9 & 3,9 & 9,2 \\
\hline & $S(112)$ & 75,8 & 50 & 29,4 & 66,9 & 77,6 & 21,4 & 60,7 & 80,3 & 35,7 & 2,6 & 3,5 & 16,9 \\
\hline \multirow[t]{2}{*}{ K. oxytoca } & $P(1)$ & 0 & 0 & 0 & 0 & 0 & 0 & 0 & 0 & 0 & 0 & 0 & 0 \\
\hline & $S(2)$ & 0 & 0 & 0 & 0 & 0 & 0 & 0 & 0 & 0 & 0 & 0 & 0 \\
\hline \multirow[t]{2}{*}{ E. cloaca } & $P(6)$ & 83 & 16,6 & 16,6 & 50 & 66,6 & 33,3 & 33,3 & 50 & 16,6 & 16,6 & 16,6 & 50 \\
\hline & $S(2)$ & 100 & 50 & 0 & 100 & 100 & 0 & 50 & 50 & 0 & 0 & 0 & 50 \\
\hline \multirow[t]{2}{*}{ P. mirabilis } & $\mathrm{P}(8)$ & 50 & 37,5 & 0 & 25 & 62,5 & 37,5 & 75 & 62,5 & 0 & 12,5 & 0 & 75 \\
\hline & $S(13)$ & 30,7 & 76,9 & 46,1 & 69,2 & 84,6 & 53,8 & 92,3 & 84,6 & 15,3 & 69,2 & 0 & 84,6 \\
\hline \multirow[t]{2}{*}{ C. freundi } & $P(7)$ & 33,3 & 0 & 0 & 71,4 & 71,4 & 14,2 & 42,8 & 71,4 & 0 & 0 & 0 & 14,2 \\
\hline & $S(7)$ & 85,7 & 57,1 & 57,1 & 85,7 & 85,7 & 28,5 & 57,1 & 85,7 & 57,1 & 0 & 57,1 & 57,1 \\
\hline
\end{tabular}




\begin{tabular}{|c|c|c|c|c|c|c|c|c|c|c|c|c|c|c|}
\hline \multicolumn{15}{|l|}{ ANTIBIYOTIK ADI } \\
\hline Üreyen bakteri & $\mathrm{P} / \mathrm{S}(\mathrm{n})$ & AMC\% & GN \% & AK \% & LEV\% & CiP \% & FOS\% & NITRO \% & SXT \% & $\mathrm{E} \%$ & iMP \% & MEM \% & COL \% & PTZ\% \\
\hline \multicolumn{15}{|l|}{ YARA } \\
\hline \multirow{2}{*}{ E. coli } & $\mathrm{P}(4)$ & 75 & 75 & 75 & 75 & 75 & - & - & 75 & 25 & 0 & 0 & 0 & 50 \\
\hline & $S(18)$ & 50 & 27,7 & 44,4 & 55,5 & 55,5 & - & - & 44,4 & 5,5 & 5,5 & 0 & 22,2 & 38,8 \\
\hline Pantobacter spp. & $S(1)$ & 100 & 100 & 100 & 100 & 100 & - & - & 100 & 100 & 0 & 0 & 100 & 0 \\
\hline S.marcescens & $S(3)$ & 100 & 0 & 0 & 0 & 0 & - & - & 0 & 0 & 0 & 0 & 33 & 33 \\
\hline K. oxytoca & $P(1)$ & 0 & 0 & 0 & 0 & 0 & - & - & 0 & 0 & 0 & 0 & 0 & 0 \\
\hline \multirow{2}{*}{ K. pneumonia } & $\mathrm{P}(2)$ & 50 & 0 & 50 & 0 & 50 & - & - & 0 & 0 & 0 & 0 & 0 & 0 \\
\hline & $S(6)$ & 33,3 & 33,3 & 50 & 50 & 66,6 & - & - & 44,4 & 33 & 0 & 16,6 & 16,6 & 50 \\
\hline
\end{tabular}

\section{Tablo 4: GSBL pozitif Gram negatif bakterilerin solunum örneklerinde antibiyotiklere direnç oranları}

ANTIBIYOTIK ADI

\begin{tabular}{|c|c|c|c|c|c|c|c|c|c|c|c|c|c|c|}
\hline Üreyen bakteri & $\begin{array}{l}\mathrm{S} \\
\mathrm{n}\end{array}$ & $\begin{array}{c}\mathrm{AMC} \\
\%\end{array}$ & $\begin{array}{c}\mathrm{GN} \\
\%\end{array}$ & $\begin{array}{l}\text { AK } \\
\%\end{array}$ & $\begin{array}{l}\text { LEV } \\
\%\end{array}$ & $\begin{array}{l}\text { CiP } \\
\%\end{array}$ & $\begin{array}{c}\text { FOS } \\
\%\end{array}$ & $\begin{array}{c}\text { NiTRO } \\
\%\end{array}$ & $\begin{array}{c}\text { SXT } \\
\%\end{array}$ & $\begin{array}{c}E \\
\%\end{array}$ & $\begin{array}{l}\text { IMP } \\
\%\end{array}$ & $\begin{array}{c}\text { MEM } \\
\%\end{array}$ & $\begin{array}{c}\mathrm{COL} \\
\%\end{array}$ & $\begin{array}{c}\text { PTZ } \\
\%\end{array}$ \\
\hline \multicolumn{15}{|l|}{ Balgam } \\
\hline E. coli & 8 & 50 & 62,2 & 25 & 87,5 & 87,5 & - & - & 62,2 & 12,5 & 0 & 0 & 0 & 37,5 \\
\hline K.pneumonia & 6 & 66,6 & 33,3 & 66,6 & 66,6 & 66,6 & - & - & 66,6 & 16,6 & 0 & 16,6 & 16,6 & 66,6 \\
\hline K. oxytoca & 1 & 0 & 0 & 0 & 0 & 0 & - & - & 0 & 0 & 0 & 0 & 0 & 0 \\
\hline \multicolumn{15}{|l|}{ T.Aspirat } \\
\hline E. coli & 10 & 50 & 80 & 20 & 70 & 70 & - & - & 70 & 0 & 0 & 0 & 10 & 60 \\
\hline K. pneumonia & 29 & 72,4 & 51,7 & 86,2 & 65,5 & 75,8 & - & - & 82,7 & 44,8 & 48,2 & 55,1 & 37,9 & 82,7 \\
\hline S. marcescens & 6 & 100 & 33,3 & 66,6 & 33,3 & 50 & - & - & 33,3 & 33,3 & 0 & 50 & 100 & 83,3 \\
\hline E. cloaca & 1 & 100 & 100 & 100 & 0 & 0 & - & - & 100 & 0 & 0 & 0 & 100 & 0 \\
\hline
\end{tabular}

Tablo 5: GSBL pozitif Gram negatif bakterilerin kan örneklerinde antibiyotiklere direnç oranları

ANTIBIYOTIK ADI

\begin{tabular}{|c|c|c|c|c|c|c|c|c|c|c|c|c|c|c|}
\hline Üreyen bakteri & $\begin{array}{l}\mathrm{S} \\
\mathrm{n}\end{array}$ & $\begin{array}{c}\text { AMC } \\
\%\end{array}$ & $\begin{array}{c}\text { GN } \\
\%\end{array}$ & $\begin{array}{l}\mathrm{AK} \\
\%\end{array}$ & $\begin{array}{c}\text { LEV } \\
\%\end{array}$ & $\begin{array}{c}\text { CiP } \\
\%\end{array}$ & $\begin{array}{c}\text { FOS } \\
\%\end{array}$ & $\begin{array}{c}\text { NiTRO } \\
\%\end{array}$ & $\begin{array}{l}\text { SXT } \\
\%\end{array}$ & $\begin{array}{l}E \\
\%\end{array}$ & $\begin{array}{l}\text { iMP } \\
\%\end{array}$ & $\begin{array}{l}\text { MEM } \\
\%\end{array}$ & $\begin{array}{l}\mathrm{COL} \\
\%\end{array}$ & $\begin{array}{l}\text { PTZ } \\
\%\end{array}$ \\
\hline \multicolumn{15}{|l|}{ KAN } \\
\hline E. coli & 23 & 78,2 & 47,8 & 73,9 & 73,9 & 82,6 & - & - & & 8,6 & 0 & 4,3 & 30,4 & 30,4 \\
\hline K. pneumonia & 17 & 88,2 & 70,5 & 76,4 & 58,8 & 70,5 & - & - & - & 47,0 & 5,8 & 17,6 & 35,2 & 82,3 \\
\hline K. oxytoca & 1 & 100 & 100 & 0 & 100 & 100 & - & - & 100 & 0 & 0 & 0 & 0 & 100 \\
\hline
\end{tabular}

S: Servis, AMC: Amoksisilinklavulanikasit, GN: Gentamisin, AK: Amikasin, LEV: Levfloksasin, CiP: Siprofloksasin, FOS: Fosfomisin, NiTRO: Nitrofurantoin, SXT: SulfametoksazolTrimetoprim, E: Ertapenem, IPM: Imipenem, MEM: Meropenem, COL: Kolistin, PTZ:PiperasilinTazobaktam

\section{Tartışma}

Gram negatif GSBL pozitif bakteriler sahip oldukları direnç mekanizmalarıyla birçok antibiyotik grubuna karşı direnç geliştirirler. Ülkemizde 101 makale tarama sonucunda GSBL oranı 1996-2001 yıllarında \%8,09, 2002-2007 yıllarında \%10,61, 2007-2012 yıllarında \%28,17 olduğunu bildirilmiştir [5].
Kahraman ve ark. [6] K. pneumoniae izolatlarının 415'i (\%48) idrar, 91'i (\%10) kan, 76'sı (\%9) yara, 52'si (\%6) trakeal-aspirat, $19^{\prime} u$ (\%2) balgam ve $218^{\prime i}$ (\%25) diğer klinik örneklerden izole edilmiş, GSBL pozitifliği bütün izolatlarda $\% 55$ olarak saptamışlardır. Uzak Doğu ülkelerinde kan dolaşım enfeksiyon etkeni olan E. coli ve K. pneumoniae izolatlarında GSBL pozitiflik oranları $\% 18,5-55,5$ ve $\% 16,5-55,7$ olarak bulunmuştur $[7,8]$. 
Bizim çalışmamızda 1735 Gram negatif üreyen bakterin 1041 (\%60)'i GSBL pozitif olarak saptanmıştır.

GSBL pozitifliği üriner sistem enfeksiyon etkenlerinde sıkça karşımıza çıkmaktadır. Toplum kaynaklı üriner sistem enfeksiyonu gelişmesinde riskfaktörleri; son üç ayda antibiyotik kullanımı, 60 üzeri yaş grubu, son 3 ay için de hastanede yatış öyküsü, DM, cinsiyet (erkek hastalarda çok yaygın) farkı, sık tekrar eden idrar yolu enfeksiyonu, yakın zamanda uygulanan üriner kateterizasyon ve ayaktan tedavi merkezlerinde takip öyküsü gibi bulgular olarak belirlenmiştir [9]. Üriner sistem enfeksiyon etkenleri arasında en başta E.coli olmak üzere K.pneumoniae, P.mirabilis, E.faecalis ve S.saprafiticus dur. 20082013 yılları arasında Güney Kore'de ayaktan ve yatan hastalara ait 29,584 idrar örneğinde retrospektif bir çalışmada idrar yolu enfeksiyon etkeni olan 277 GSBL pozitif K.pneumoniae ve E.coli etkenine ait antibiyotik duyarlılık sonuçlarına göre trimetoprim/sulfometoksazole $\% 65,7$, siprofloksasine \%79,3 dirençli olduğu gözlenmiştir [10]. Coşkun ve ark [11] GSBL üreten K.pneumoniae suşları için nitrofurantoin ve fosfomisine duyarlılığı \%85,7 ve \%83,7 E coli suşları için \%91,5 ve $\% 90,1$ olarak saptamışlardır. Özcerezci ve ark. [12] E. coli suşlarında amikasin \%9,8, trimetoprim/sulfometoksazol \%39, fosfomisin \%6,3 ve nitrofurantoine ise direnç saptanmamıştır. Özel ve ark. [13]'nın çalışmasında soyutlanan 463 E. coli suşunun \% 97,6'si fosfomisine duyarlı bulunmuştur. Bizim çalışmamızda, idrar örneklerinde en sık E.coli izole edildi. Dirençin en düşük olduğu antibiyotikler poliklinik hastalarda imipenem\%2.2, meropenem \%2.7, ertapenem \%8.3, fosfomisin \%4, 1,nitrofurantoin \%9,1, amikasin \%5,5 olarak en etkili antibiyotikler olarak belirlenmiştir. Servis hastalarında ise imipenem $\% 1,6$, meropenem $\% 2,9$, ertapenem $\% 11,3$, fosfomisin \%12,6 nitrofurantoin \%19,1, amikasin \%9,4 oranlarında en etkili antibiyotikler olduğu belirlenmiştir.

Hastane kaynaklı bakteriyemiler de GSBL üreten bakteriler daha çok izole edilmektedir. Ndir ve ark. [14] çalışmalarında üreyen GSBL pozitif Enterobacteriaceae izolatlarının \%11,6'sının toplum kaynaklı, \%88,4'ünün ise hastane kaynaklı olduğunu bildirmişlerdir. European Centre for Disease Prevention and Control'ün (ECDC) 2017'de yayınladığı on beş ülkenin katılımı ile oluşturulan raporda; kan dolaşımı enfeksiyonlarına neden olan etkenlerinden en sık izole edilen Gram negatif etkenin Klebsiella spp. olduğu açıklanmıştır [15]. Avrupa ülkelerinden bildirilenin aksine ülkemizde kan dolaşımı enfeksiyonlarına neden olan Gram negatif bakteriler içinde E.coli ilk sırada bulunmakta ve görülme sıklığı ise
\% 5.7-13'tür [16-17-18]. Bayraktar ve ark.[19] üç yıllık süre içinde 632 adet E. coli izolatından 224 (\%35)'ünün ve 439 adet K. pneumoniae izolatından 137 (\%31)'sinin GSBL ürettiği saptanmış, GSBL pozitif E. coli ve K. pneumoniae suşlarının oranı 2014, 2015 ve 2016 yılları için sırasıyla E. coli için \%23, $\% 36, \% 48$, K.pneumoniae için \%23, \%32, \%37 olarak tespit edilmiş, yıllar içindeki GSBL artışı hem $E$. coli $(p<0.001)$ hem de K. pneumoniae $(p=0.011)$ için istatistiksel olarak anlamlı bulunmuş, GSBL pozitif E. coli ve K. pneumoniae suşlarının en duyarlı olduğu antibiyotikler karbapenem sınıfı antibiyotikler, amikasin ve kolistin olarak bildirilmişlerdir. Bizim çalışmamızda, kan örneklerinde en sık E. coli izole edilmiştir. Direncin en düşük olduğu imipenem $\% 0$, meropenem $\% 4,3$ ve ertapenem $\% 8,6$ en etkili antibiyotikler olduğu belirlenmiştir.

Yapılan ulusal bir çalışma da solunum yolu GSBL üreten suşların izole edilme sıklıklarına göre en sık K. pneumoniae ardından E. coli olarak bildirmiş, GSBL üreten bakterilerde imipenem direncini $\% 27,6$ ve meropenem direncini $\% 3,9$, ertapenem direncini ise \%47,4 olarak bildirmişlerdir [20]. Fırsatçı patojenlerde özellikle solunum yolu örneklerinde üremekte ve yoğun antibiyotik direncine sahip olmaktadır [21]. Koçak ve ark.[22] çalışmalarında büyük çoğunluğu $(\% 79,5)$ yoğun bakımda yatmakta olan hastalardan izole edilen $\mathrm{K}$. pneumoniae izolatlarında karbapenem direnci \%40 civarında saptamışlardır. Bizim çalışmamızda, balgam örneklerinden en sık E. coli izole edilmiştir. Direncin en düşük olduğu antibiyotikler imipenem \%0, meropenem \%0, ertapenem \%12,5, kolistin $\% 0$ olarak belirlenmiştir. Trakeal aspirat örneklerimizde en sık K. pneumoniae izole edilmiştir. Direncin en düşük olduğu antibiyotikler ise imipenem \%48,2, meropenem \%55,1, ertapenem $\% 44,8$ ve kolistin \%37,9 olarak saptanmıştır.

Çaycı ve ark. yara enfeksiyonu etkenlerinden en sık E. coli, takibinde MSSA (Metisilin duyarlı S. aureus) ve P.aeruginosa üretmiş Enterobacteriacea türlerinin en duyarlı olduğu antibiyotikleri amikasin, imipenem ve meropenem olarak bildirirken, Avcıoglu ve ark. GSBL pozitiflik oranını E. coli için $\% 43,8$, K.pneumoniae için $\% 4,5$ olarak bulmuş ve en yüksek antibiyotik direnç oranı \%70,8 ile ampisiline, en az direnç oranı \%2 ile imipenem olarak bildirken ulusal başka bir çalışmada yara yeri örneklerinde GSBL oranı \% 41,7 en sık izole edilen etken E.coli, en duyarlı antibiyotik ise \%0,8 ile meropenem ve imipenem olmuştur. [23-24-25]. Bizim çalışmamızda, yara örneklerinde en sık E.coli izole edilmiştir. Direncin en düşük olduğu antibiyotikler poliklinik hastalarında imipenem \%0, meropenem $\% 0$, ertapenem $\% 25$, kolistin $\% 0$ olarak belirlenmiş 
iken servis hastalarında ise imipenem \%5,5, meropenem \%0, ertapenem \%5,5, kolistin \%22,2 olarak tespit edilmiştir.

Çalışmamızda yer alan plevral sıvı örneğinin iki adet eklem sıvısı örneğinin bir adet olasından dolayı değerlendirmeye alınmamıştır.

\section{Sonuç}

Elde etmiş olduğumuz bütün veriler eşliğinde; antibiyotik direncinin bölge bölge değişimlerinin aralıklı olarak takip edilmesi, antibiyotik duyarlılık testleri sonuçlarına göre direnç durumundaki değişimlerin ortaya konulması, antibiyotik grubu ilaçların direnç oranlarının azaltılması amacıyla bu konuda eğitim yapılması ve kullanıma yönelik yeni politikalar geliştirilmelidir.

\section{Çıkar Çatışması}

Yazarlar bu makale ile ilgili herhangi bir çıkar çatışması bildirmemişlerdir.

\section{Kaynaklar}

1. Murray PR, Baron EJ, Jorgensen JH. Manual of Clinical Mikrobiology. Başustaoğlu A, Kubar A, Yıldıran ŞT, Tanyüksel M (Çevirenler). 9. baskı, İstanbul: Atlas Basımevi, 2007; 8: 1721-92

2. Abayneh M, Worku T. P Prevalence of multidrug-resistant and extended-spectrum beta- lactamase (ESBL)-producing gramnegative bacilli: A meta-analysis report in Ethiopia. Drug Target Insights. 2020; 14: 16-25.

3. Moges F, Eshetie $S$, Abebe $W$ et al. High prevalence of extendedspectrum beta-lactamase-producing gram-negative pathogens from patients attending Felege Hiwot Comprehensive Specialized Hospital, Bahir Dar, Amhara region. PLoS One. 2019; 14: 0215177.

4. EUCAST 2019. The European committee on antimicrobial susceptibility testing. Breakpoint tables for interpretation of MICs and zone diameters. Version 9.0, 2019. http://www.eucast.org .

5. Aykan ŞB, Çiftçi İH. Türkiye'de idrar kültürlerinden izole edilen E. coli suşlarının antibiyotiklere direnç durumu: Bir meta analiz. Mikrobiyol Bul 2013; 47: 603-18.

6. Kahraman EP, Karakeçe E, Erdoğan F, Uluyurt H,Köroğlu M, Çiftçi IH. Klebsiella pneumoniae izolatlarının antibiyotikler direnç durumlarının değerlendirilmesi ortadogutipdergisi 2017.

7. Kim YK, Pai H, Lee HJ, et al. Bloodstream infections by extendedspectrum beta-lactamase-producing Escherichia coli and Klebsiella pneumoniae in children: epidemiology and clinical outcome. Antimicrob Agents Chemother 2002; 46: 1481-91.

8. Quan J, Zhao D, Liu L, et al. High prevalence of ESBL-producing Escherichia coli and Klebsiella pneumoniae in community-onset bloodstream infections in China. J Antimicrob Chemother 2017; 72: $273-80$.
9. Tükenmez T.E, Mülazımoğlu L. Toplum kökenli infeksiyonlarda genişlemiş spektrumlu $\beta$-laktamazlar ve klinik önemi. Klimik Derg. 2012; 25: 94-8.

10. Cho YH, Jung SI, Chung HS et al. Antimicrobial susceptibilities of extended-spectrum beta- lactamase-producing Escherichia coli and Klebsiella pneumoniae in health care-associated urinary tract infection: focus on susceptibility to fosfomycin, Int Urol Nephrol 2015; 47: 1059-66.

11. Coşkun $M$, Uyanık M, Ağan İ. Hastanede yatan hastaların üriner sistem infeksiyonlarından izole edilen genişlemiş spektromlu beta laktamaz üreten Klebsiella pneumonia ve Escherichia coli suşlarının fosfomisin ve nitrofrantoine duyarlılıklarının araştırılması. ANKEM dergi 2016; 30: 37-41.

12. Özçerezci Ö, Savcı Ü. Yeni doğan yoğun bakım ünitesinde preterm ve term bebeklerde genişlemiş spektromlu bete laktamaz üreten gram negatif bakteri enfeksiyonlarını değerlendirmesi. J.Pediatri Emeg İntensive Care Med. 2019; 6: 91-7.

13. Özel $Y$, Vardar-Ünlü G. Üriner sistem infeksiyonlarından soyutlanan Escherıchı coli suşlarında fosfomisinin in vitro etkinliği. ANKEM Dergi, 2015; 29: 95-8.

14. Ndir A, Diop A, Faye PM, et al. Epidemiology and Burden of Bloodstream Infections Caused by Extended- SpectrumBetaLactamase Producing Enterobacteriaceae in a Pediatric Hospital in Senegal. PLoS One 2016; 11: 0143729.

15. European Centre for Disease Prevention and Control. Healthcareassociated infections acquired in intensive care units. In: ECDC. Annual epidemiological report for 2015; 4-5.

16. Er H, Aşık G, Yoldaş Ö, et al. Kan kültürlerinde izole edilerek tanımlanan mikroorganizmaların ve antibiyotik direnç oranlarının belirlenmesi. Türk Mikrobiyol Cem Derg. 2015; 45: 48-54.

17. Küçükateş $E$, Gültekin N. Yoğun bakım ünitelerinde yatan hastaların kan kültürlerinden izole edilen mikroorganizmalar ve antimikrobiyal duyarlılıkları. Med Bull Haseki 2016; 54: 97-102.

18. Şirin $\mathrm{MC}$, Ağuş $\mathrm{N}$, Yılmaz $\mathrm{N}$ ve ark. Yoğun bakım ünitelerinde yatan hastaların kan kültürlerinden izole edilen mikroorganizmalar ve antibiyotik duyarlılıkları. Turk Hij Den Biyol Derg. 2017; 74: 269-78.

19. Bayraktar B, Pelit S, Bulut M, et al. Genişlemiş Spektrumlu Beta Laktamaz Üreten Escherichia coli ve Klebsiella pneumoniae Kan Dolaşımı Enfeksiyonlarında Antibiyotik Direnç Oranlarının Yıllar İçindeki Değişimi Med Bull Sisli Etfal Hosp 2019; 53: 70-5 .

20. Şen $P$, Yula E, Demirdal $T$, et al. Solunum yollarından izole edilen genişlemiş spektrumlu ve indüklenebilir beta-laktamaz üreten bakterilerin direnç oranları.ortadogutipdergisi 2017; 4: 170-6. 
21. Bahçecil.ÇeşitliKlinikÖrneklerden İzoleEdilen Stenotrophomonas maltophilia Suşlarının Dağılımı ve Antimikrobiyal Duyarlııkları: 8 Yılık Çalışma. Dicle Tıp Dergisi. 2021; 48: 147-52.

22. Koçak A, Yayla B, Güçlü A ve ark. Adana'da Bir Üniversite Hastanesinde İzole Edilen Solunum Yolu Patojenleri ve Antibiyotik Direnç Profillerinin Değerlendirilmesi. Türk Mikrobiyoloji Cem Derg 2019; 49: 226-32.

23. Çaycı $Y$, Torun $E$, Bilgin $K$, et al.Yara Yeri Örneklerinden İzole Edilen Etkenler ve Antibiyotik Direnç Profilleri.Düzce Üniversitesi Sağlık Bilimleri Enstitüsü Dergisi 2021; 11: 123-8.
24. Avcıoğlu F, Behçet M, Karabörk Ş, et al. Yara Örneklerinden İzole Edilen Mikroorganizmaların Antimikrobiyal Direnç Oranları - Üç Yılık Değerlendirme .Düzce Üniversitesi Sağlık Bilimleri Enstitüsü Dergisi 2019; 9: 110-4 .

25. Bahçeci İ. Microorganisms that Reproduce in Wound Cultures in Rize Region and Their Antimicrobial Susceptibility. Middle Black Sea Journal of Health Science. 2020; 6: 358-68. 